\title{
Bullshit and Organization Studies
}

\author{
Christensen, Lars Thøger; Kärreman, Dan; Rasche, Andreas
}

Document Version

Accepted author manuscript

Published in:

Organization Studies

DOI:

$10.1177 / 0170840618820072$

Publication date:

2019

License

Unspecified

Citation for published version (APA):

Christensen, L. T., Kärreman, D., \& Rasche, A. (2019). Bullshit and Organization Studies. Organization Studies, 40(10), 1587-1600. https://doi.org/10.1177/0170840618820072

Link to publication in CBS Research Portal

\section{General rights}

Copyright and moral rights for the publications made accessible in the public portal are retained by the authors and/or other copyright owners and it is a condition of accessing publications that users recognise and abide by the legal requirements associated with these rights.

Take down policy

If you believe that this document breaches copyright please contact us (research.lib@cbs.dk) providing details, and we will remove access to the work immediately and investigate your claim. 


\section{Bullshit and Organization Studies \\ Lars Theger Christensen, Dan Kärreman, and Andreas Rasche}

Journal article (Accepted manuscript*)

\section{Please cite this article as:}

Christensen, L. T., Kärreman, D., \& Rasche, A. (2019). Bullshit and Organization Studies. Organization Studies, 40(10), 1587-1600. https://doi.org/10.1177/0170840618820072

DOl: https://doi.org/10.1177/0170840618820072

Copyright (C) The Author(s) 2019. Reprinted by permission of SAGE Publications.

* This version of the article has been accepted for publication and undergone full peer review but has not been through the copyediting, typesetting, pagination and proofreading process, which may lead to differences between this version and the publisher's final version AKA Version of Record.

Uploaded to CBS Research Portal: May २०२० 


\title{
Bullshit and Organization Studies
}

\author{
Forthcoming in: Organization Studies
}

\author{
Lars Thøger Christensen (1tc.msc@,cbs.dk) \\ Copenhagen Business School \\ CBS Centre for Corporate Social Responsibility \\ Dalgas Have 15, 2000 Frederiksberg \\ Denmark
}

\author{
Dan Kärreman (k.msc@ecbs.dk) \\ Copenhagen Business School \\ Department of Management, Communication, and Society (MSC) \\ Dalgas Have 15, 2000 Frederiksberg \\ Denmark
}

\author{
Andreas Rasche (ar.msc@cbs.dk) \\ Copenhagen Business School \\ CBS Centre for Corporate Social Responsibility \\ Dalgas Have 15, 2000 Frederiksberg \\ Denmark \\ $\&$ \\ Stockholm School of Economics \\ Mistra Centre for Sustainable Markets (MISUM) \\ Box 6501, 11383 Stockholm \\ Sweden
}




\title{
Bullshit and Organization Studies
}

\begin{abstract}
:
Bullshit is a ubiquitous communication practice that permeates many dimensions of organizational life. This essay outlines different understandings of bullshit and discusses their significance in the context of organization studies. While it is tempting to reject bullshit as corrosive to rational organizational practice, we argue that it is necessary to understand its organizational significance and performative nature more systematically. We outline different social functions of bullshit focusing on two particular types of managerial practices in which bullshit is likely to play a significant role: commanding and strategizing. On this backdrop, we consider bullshit in terms of the messages, senders and receivers involved, focusing especially on the dynamics between these dimensions in the context of organizations. The final part of this essay debates the reasons why bullshit, which is recognized by organizational members, is rarely called and rejected explicitly.
\end{abstract}

Keywords: bullshit, organization studies, communication, bullshit receptivity 


\section{INTRODUCTION}

Current US President Donald Trump is often called a liar. The Washington Post recently reported that he made 1,318 false statements in the first nine months of his Presidency (that's about five per day; Kessler, Rizzo \& Kelly, 2018). Yet, President Trump is not only a liar; he is also a bullshitter. During his campaign, he stated that millions of illegal immigrants will be deported once he is elected into office (Berenson, 2015). This statement, Princeton Professor Harry Frankfurt (2016) argued in an article on Time.com, was bullshit because Mr. Trump could not have been certain that he, as president, would have the actual authority to decide on deportations. What makes Trump a bullshitter, according to Frankfurt, is that he doesn't seem to care much whether such statements are actually true.

Yet, bullshit is not just about Trump. Bullshit keeps “piling up”, as Frankfurt suggested in an interview on Jon Stewart's The Daily Show in 2015. Considering the current communicative landscape and attempts by leaders to evade responsibility or justify questionable decisions, it certainly looks as if there is more and more of it. Understood as obscure, empty or pretentious talk (Cohen, 2006; Hardcastle \& Reisch, 2006; Kelly, 2014), bullshit seems to be pervasive especially in contexts where power is exercised. Given recent developments in politics, journalism and social media, it is tempting to conclude that bullshit is the new normal. The increase in fake news, for example, and the deceptive statements of corporate and political leaders seems to warrant descriptors of society as "post-factual" (Manjoo, 2008) or "post-truth" (Keyes, 2004). In this context, the need to expose the bullshit - as many popular talk shows try to do these days - seems more pressing than ever. Certainly, the communicative practices of the current American president underscore the feeling of urgency when it comes to "calling the shit." 
Along with Frankfurt and many other scholars and social critics, we are stunned and outraged by the amount of far-fetched claims in public debate and corporate communication. This is our point of departure. Yet, although outrage can be a significant driving force for critique and change, it may not be the most suitable approach if we want to understand the role bullshit plays in social and organizational life. The aim of this essay is to contribute to such understanding. To that purpose, we need to acknowledge that bullshit is a ubiquitous phenomenon that permeates all types of social interaction (Mears, 2002). From that perspective, we consider bullshit in terms of messages, senders and receivers, focusing in particular on the dynamics between these dimensions in the context of organization.

In this endeavor, we have been inspired by Frankfurt's (2005) elegant writings on the topic as well as by other philosophers who have extended his ideas (e.g., Cohen, 2006; Hardcastle \& Reisch, 2006). With its primary focus on organizations, our discussion is triggered also by Spicer's notion of Business Bullshit $(2013,2017)$ that links bullshit to phenomena such as management fashions and the use of jargon highlighting opportunities and, especially, problems related to its proliferation in and around organizations (see below). Our essay extends Spicer's reflections in three important ways. First, we take our point of departure in how different understandings of the term have shaped the discussion of bullshit. Second, while Spicer's main emphasis remains on the problematic aspects of bullshit, we aim to debate its organizational significance and performative nature more systematically, mostly by focusing on two particular types of managerial practices in which bullshit is likely to play a significant role: commanding and strategizing. Finally, we put more emphasis on discussing the reasons why bullshit, which is recognized by organizational members, is rarely called and rejected explicitly. 


\section{BULLSHIT WE LIVE BY}

In everyday conversation, according to the Oxford English Dictionary, bullshit is a slang profanity exclamation meaning "nonsense", especially used as an affective rejection of talk viewed as disingenuous, untrue or outright stupid. As a noun, bullshit may be described as exaggerated, pompous or foolish talk, whereas the verb bullshitting - means to talk idly or boastfully sometimes with the intention of deceiving or misleading. While originally perceived as rude and vulgar language, the term "bullshit" has in many ways become normalized in mundane language.

The act of bullshitting seems to be normalized, too. We encounter bullshit in a wide variety of social practices including political slogans, branding, professional jargon, comedy and other situations where hyperbole, esoteric language or humor is the norm (e.g., Barnes, 1994; Maes \& Schaubroeck, 2006; Mears, 2002). In many such situations, we live with the bullshit without calling it. Since the occurrence of bullshit is context dependent, we can expect that organizations are exposed to it in different ways. For instance, advertising and public relations agencies and consultants are likely to be "full of it", and in some cases even make the production of bullshit an important pillar of their business (Graeber, 2018; Spicer, 2017). By contrast, high reliability organizations, that is, organizations that need to avoid failure at any expense (e.g., nuclear power plants; Weick \& Sutcliffe, 2015), might be expected to have lower degrees of bullshit in and around them, although this is not always the case as we shall see later.

While we may be inclined to express our contempt for bullshit when it emanates from sources of power, bullshitting is often accepted - sometimes encouraged - in social interaction. Messages from car dealers, realtors or advertisers, for example, are 
usually expected to seduce, charm or placate its audiences and may therefore not provoke explicit exclamations of disdain or disbelief (Kimbrough, 2006; Maes \& Schaubroeck, 2006). In friendship interaction such as joking, teasing or gaming (Barnes, 1994; Mears, 2002) bullshit may even produce respect and admiration. Beyond friendship and close relationships, bullshit is sometimes expected and appreciated among strangers where politeness and wit can serve to ease and lubricate social interaction (Maes \& Schaubroeck, 2006). Straight talk may be closer to the true feelings of the participants, rather than good manners, but runs the risk of sacrificing peace and comfort (Kimbrough, 2006).

In addition to its socializing functions, bullshit may also help social actors explore "the contours and boundaries of self and reality" (Mears, 2002, p. 236) by expressing certain views or ideas. Such explorative function of bullshit is described by Frankfurt (2005) in his discussion of so-called "bull sessions", i.e. conversations in which participants openly try out different perspectives and attitudes without anyone assuming a strong commitment from the speaker to what $\mathrm{s}(\mathrm{he})$ is saying (see also Allen, Allen \& McGoun, 2012). The main purpose of a bull session is to allow participants a forum in which they can experience themselves expressing perspectives they would otherwise not share with others (e.g., about contested topics such as religion). The social meaning and impact of bullshit, thus, is highly contextual, depending on the setting in which it occurs, the participants involved, the power of its producers, its directionality, the level of improvisation, and the scope of its consequences.

While bullshitting in everyday social interaction is a frequent social practice with ceremonial character - a practice in which many of us participate without noticing it - we are increasingly engaged when it comes to the detection and sharing 
of bullshit from powerful individuals and institutions. Whereas journalists and scientists (at least in open democratic societies) are officially in the business of "bullshit detection", the ability to "call the shit" is today far more widely distributed. Under the impact of digital media and the types of information access they afford, the possibility to exchange, share and contest messages and worldviews from politicians and corporate leaders has expanded dramatically over the last few decades to the effect that few, if any, sources of authority stand unchallenged (e.g., Gulbrandsen \& Just, 2011). In this communication environment, bullshit is likely to thrive. When all authorities can be challenged, audiences may at once expect more and less truth; more because this is what the existence of alternative voices seems to promise, less because what was presented as factual yesterday is today exposed as false.

The ability to "call the shit" is often considered a cultural competence because it signals a capacity to access a deeper truth behind false or manipulative statements (e.g., Pennycook et al., 2015). Yet, although references to "truth" or "reality" are often mobilized to reject statements as bullshit, one does not need to know the truth to "call the shit". The exclamation "bullshit" is primarily a stylistic retort that indicates lack of trust, agreement with or respect for the speaker (Reisch, 2006). Such attitude may be informed by previous encounters with the speaker in question or shaped by differences in values and ideologies. For senders, veracity may not be a primary concern either (Maes \& Schaubroeck, 2006). Even with the best intentions to tell the truth, other agendas are usually at play. In addition to informing or instructing, communication serves to celebrate shared perspectives, reduce uncertainty, learn about the world, maintain relationships, express feelings, pass time, and influence or manipulate (e.g., Myers \& Myers, 1991). Since these additional functions are constitutive elements of any communicative practice, bullshit is likely to be an 
integral dimension of all social life. In order to understand its particular role in contemporary organizations, however, we need to consider its meaning more systematically.

\section{BULLSHIT AS WILLFUL MISREPRESENTATION}

A thorough examination of bullshit necessarily extends beyond its mundane uses where it often is conflated with lies, defined as false statements made with deliberate intent to deceive, propaganda, known as biased or misleading information, jargon, understood as specialized words or expressions that are difficult to understand for people outside a particular group or profession, and rhetoric, conventionally defined as the art of effective persuasion (e.g., Teitge, 2006). While bullshit may include elements of deceit and abstruse concepts, its specific characteristics differ in a number of important respects, which we shall discuss in the following.

Frankfurt's (2005) essay On Bullshit is among the few works that have subjected the notion of bullshit to a systematic conceptual analysis. By comparing bullshit to related terms such as humbug, bluff and lying, Frankfurt characterizes bullshit as a distinct social phenomenon that undermines respect for the truth. Bullshit, according to Frankfurt, is not lying. In order to lie, one needs to be aware of the truth, but seek to avoid it. The bullshitter, he claims, does not care about the truth at all: "It is just this lack of connection to a concern with truth - this indifference to how things really are - that I regard as the essence of bullshit" (Frankfurt, 2005, p. 33f). Whereas the liar misrepresents the truth, the bullshitter "misrepresents what he is up to" (p. 13). A central tenet in Frankfurt's argument, thus, is that the bullshitter willfully misleads and hides his or her enterprise. The communication practices of President Donald Trump provide many disturbing illustrations of this understanding 
of bullshit. In his conversation with Prime Minister Justin Trudeau, for example, Trump insisted that Canada has a trade deficit with the U.S. without knowing whether this is actually true or not, something he admitted recently: "I had no idea", he said in a private speech (Heer, 2018). Thus, while indifference to truth seems to be a defining feature of Trump's communication, he does not seem too concerned about keeping this fact hidden.

Beyond the example of Trump, which may be regarded as an extreme case because he is bragging about his enterprise, Frankfurt's understanding of bullshit provides an interesting differentiation from other deceptive practices. Its emphasis on willful misrepresentation, however, also constitutes a major weakness in his theorizing because it assumes intentionality and self-transparency. While it may sometimes be possible to identify the bullshitter's intentions, often the audience is left to guess what (s)he is up to. For the bullshitter, this conceptualization presumes that social actors have full access to their own intentions and motives, something which is contradicted by Frankfurt (2005) himself. Thus, he criticizes the growing focus on "sincerity" in a world of skepticism and "anti-realist doctrines": "[...] there is nothing in theory, and certainly nothing in experience, to support the extraordinary judgement that it is the truth about himself [sic] that is the easiest for a person to know" (p. 16). If social actors are generally oblivious to their own level of sincerity, we can hardly assume self-transparency when it comes to their intentions and enterprises.

Kelly (2014) draws on Frankfurt's work to argue that the absence of truthfulness is such a fundamental feature of the bullshitter that (s)he fails to care whether the audience believes the message or not as long as the bullshit is ignored or allowed to pass: "When we call bullshit, suspect someone is bullshitting, or label someone a bullshitter, we are noting that what appears to us is really an absence, an 
emptiness, a kind of phoniness in the communication from an agent who knows what his audience is willing to let him get away with and what they are not willing to let him get away with" (Kelly, 2014, p. 166f). This attitude of the bullshitter is interesting because it indicates a specific relationship between the communicator and its audience in which both parts play significant roles. Yet, Kelly fails to unfold what it means to let the bullshitter "get away" with what (s)he says. After all, such lenience is likely to serve different functions in contexts of, for example, friendship teasing, sales pitches and managerial talk.

Frankfurt and Kelly share a healthy skepticism toward vacuous language and indifference to the veracity of a statement. Their theorizing, however, have three shortcomings. First, they seem to imply a straightforward notion of truth that ignores, as Reisch (2006, pp. 37f) points out, “[...] that our collective beliefs about what is true - about the world, about how it works, about our place in it - are extremely diverse and often contradictory." Second, they assume that intentions of bullshitters are always evident. While social actors sometimes know the motives of themselves and others, they are as likely to be in the dark about them. As Cohen (2006) points out, people often pass on bullshit without any intention to misdirect. Third, and relatedly, by focusing on bullshit as a harmful enterprise, they tend to downplay the role of vague language in processes of lubricating social interaction and exploring new dimensions of self and reality (Mears, 2002; see also Allen et al., 2012).

\section{BULLSHIT AS UNCLARIFIABLE UNCLARITY}

Since it is possible to emit bullshit without intending to do so, Cohen (2006) suggests looking at the bullshit itself rather than the bullshitter: "For reasons of courtesy, strategy, and good evidence, we should criticize the product, which is visible, and not 
the process, which is not" (Cohen, 2006, p. 135). According to Cohen, bullshit can be identified by looking at the features of texts. Specifically, he identifies bullshit as "unclarifiable unclarity", that is, discourse that cannot be rendered clear or unobscure. While Cohen does not explain what "clear" means, he adds that unclarity may relate to the construction of a sentence itself and to its use in a particular context. One example of unclarifiability is that terms can easily be negated or exchanged without altering the plausibility of a statement. Although it may be objected that Cohen's focus on semantics ignores the pragmatic function of bullshit (Reisch, 2006), his contribution is important, because it shows that indifference to the truth by the bullshitter is not necessary for bullshit to occur. In the shape of unclarifiable statements, bullshit can be (re)produced by honest persons who do not realize what they are doing, either because they are expected to speak in a certain manner in their particular jobs or because they seek for words to explain what they mean.

Pennycook et al. (2015) extend this view by approaching bullshit from a psychological perspective. Instead of examining the role of the bullshitter and his or her intentions, they focus on the receptivity to bullshit at the level of the bullshitee. To investigate such receptivity, they concentrate on receiver acceptance of a particular type of bullshit, what they call "pseudo-profound bullshit." In contrast to bullshit that may be described as pure nonsense, pseudo-profound bullshit is constructed to give the impression of some deeper meaning. Pseudo-profound bullshit is deliberately designed to simulate sophistication by obscuring or evading clarity. As such, it may resemble community jargon, including academic terminologies, as well as some dimensions of political and managerial talk. According to Pennycook et al., individuals vary significantly in their tendency to ascribe profundity to such bullshit statements. Specifically, they claim that bullshit receptivity correlates with lower 
cognitive skills, religious and paranormal beliefs, and what they call "an uncritically open mind" (p. 559). Bullshit sensitivity, by contrast, is positively correlated with analytic cognitive style and a general skepticism to paranormal explanations. Pennycook et al.'s study, however, fails to acknowledge that tolerance for bullshit is contextual and occasionally reflects social skills (Maes \& Schaubroeck, 2006) and good manners (Kimbrough, 2006). Moreover, their discussion seems to ignore the pervasiveness of bullshit receptivity in academe where bullshit sensitivity is considered a defining virtue. In order to explain bullshit receptivity in such contexts, we obviously need to consider its broader social role as a potential source of identity, belonging and power.

In spite of their various limitations, these scholarly considerations are all essential in capturing the concept's complexity as a social phenomenon (see Table 1 for an overview of the different understandings of bullshit discussed up to this point). While bullshit is usually manifested in specific statements, its impacts hinge on a dynamic interplay between messages and communicators taking on different positions and playing different roles. Our discussion of bullshit and its functions in contemporary organizations, accordingly, consider all three dimensions of the phenomenon: the bullshit, the bullshitter, and the bullshitee.

INSERT TABLE 1 ABOUT HERE 


\section{SHITTY ORGANIZATIONAL BULLSHIT}

Spicer's $(2013,2017)$ reflections on what he calls Business Bullshit provides a first illustration of the concept's relevance for organization studies. According to Spicer, much of what is said in contemporary organizations is bullshit because it is disconnected from organizational practices and "avoids reference to the truth" (2013, p. 659). Such talk, he claims, is not only meaningless, but also ineffective. Although he recognizes instances where bullshit might serve beneficial social purposes, his primary focus is on its problematic consequences.

Bullshit, according to Spicer, has multiple negative effects on organizations, including decoupling of talk and action, blindness to entrenched assumptions and a tendency to repress discordant voices and perspectives. Spicer (2017) seems to argue that bullshit has corroded organizational decision-making to such an extent that Chester Barnard's famous dictum that individual's lack of rationality can be compensated by the wisdom of the organization has become utterly corrupted. He provides example by example of how important issues are bludgeon into bullshit, where the common denominator is the banality and normalcy, rather than evil, at play.

It could be argued that a significant source of organizational bullshit is the increasing propensity to let subjective positions and self-presentations play a bigger role in contemporary organizations - something that might undermine trust and rational argumentation. Whatever the reason, the major problem with organizational bullshit is that vacuous or unclarifiable talk might cause members to neglect problems, either because they are too self-confident about the profundity of their own talk or because they are silenced by similar talk by others. Terms like "win-win situations" and "leverage", for example, often sound convincing because they are presented in ways that make them seem unavoidable and highly desirable. In such 
cases, bullshit can undermine constructive criticism and feedback loops, which are needed for organizational learning (Argyris, 1990; Senge, 1990). Diane Vaughan's (1996) discussion of NASA's Challenger disaster is a case in point. She rejects the hypothesis that the explosion was caused by amoral mid-level managers who deliberately violated rules. Instead, she shows that NASA's internal talk about "acceptable risk" and a "can-do attitude" as well as reference to other airy terms (e.g., "action items", "waivers") changed the workgroup culture and hence also the assessment of situations: "Routinely used and taken-for-granted, the language did not lend itself to sending signals of potential danger" (Vaughan, 1996, p. 252).

Bullshit, which is not called, is likely to produce cynicism and prevent organizational members from taking relevant claims seriously. As such, it can manipulate organizational reality and increase domination (see also Mears, 2002). Specifically, Fleming and Spicer (2014, p. 242) see manipulation as a way to "limit the issues that are discussed or fit issues within (what are perceived to be) acceptable boundaries." Following this logic, bullshit may be used to narrow organizational agendas, for instance by exploiting ambiguity, shaping the presumptions in a debate, and preventing certain issues from arising (see also, Deetz, 1992).

Spicer (2017) explicitly sets out an agenda to engage in bullshit-reduction. We share his outlook and ultimate objective. At the same time, however, we believe that it is necessary to take a closer look at why bullshit is piling up in organizations. It is not enough to say that organizational bullshit is bad and that we need less of it - nobody argues that it is good or that we need more. The important task is to understand more about what it is and what role it plays in organizations. In that endeavor, insight into the role of bullshit in the wider society, as discussed above, is essential. Spicer (2017) 
leaves us in no uncertain terms about the stupidity of bullshit. Below we discuss the performative functions of bullshit.

\section{SHIT THAT PERFORMS}

Much talk that materializes in organizations may be labeled bullshit because it is airy or vague and seemingly disconnected from other and more important organizational practices. The strategy, the diversity plan, the vision, the corporate culture one-pager, the CSR policy are all examples of airy talk tainted by "unclarifiable unclarity" (Cohen, 2006). Such communication, however, is not necessarily superfluous. Simple and ambiguous statements can validate managerial decisions, actions and omissions or be used to impress, seduce or unite a heterogeneous audience (cf. Eisenberg, 2007). Notions such as "strategic philanthropy" (Porter \& Kramer, 2002) and "shared value" (Porter \& Kramer, 2011), for example, have in many cases legitimized CSR activities vis-à-vis investors and made actions in support of responsible business practices appear rational to financial markets. Bullshit can also help rationalize managerial decisions among members, for example by positioning unpopular restructuring programs as "right-sizing" or "cutting edge" thinking that will bring a number of benefits to the organization. As a managerial communication genre, thus, bullshit can perform important legitimizing functions.

As these brief examples indicate, organizational bullshit cannot be reduced to a specific type of message, sender or receiver, but transpires in a dynamic relation between all three dimensions. Importantly, this does not imply that the bullshit is necessarily accepted by all participants; rather that it is expected or considered "normal" in particular situations. This expectation may explain why bullshit, which is recognized and perhaps even rejected by participants, is not always openly and 
explicitly called. In the remainder of this essay we unfold these observations by focusing on two particular types of managerial practices in which bullshit is likely to play a significant role: commanding and strategizing. These practices involve the setting of direction for the organization and its members, the former focused on the here and now, the latter on the future. In both cases, we consider the interplay between the bullshit, the bullshitters and the bullshitees.

Commanding as bullshit. Bullshit may be used to simulate, in the Baudrillardian sense, employee participation and agency. In many countries and cultural contexts, managers cannot explicitly command employees into action even though this is in fact what they are expected to do. As Jackall (1988) points out, members in modern organizations are unlikely to respond well to explicit commands and control practices, either because of their expertise, their experience, or because direct commands are considered brutish and unfashionable. Bullshit provides a workaround for managers that need to provide guidance and direction, yet being unable to do so explicitly. While vague and vacuous talk may be a suboptimal outcome of management practice - as Jackall (1988) illustrates, euphemisms are likely what is aimed for in such situations - bullshit offers a sense of commanding without commands, direction without directives. As such, it upholds existing power positions while allowing all involved the possibility to save face (cf. Eisenberg, 1984, 2007).

Consider, for example, how employee appraisals, this great modern tool for human resource management, typically are sold as "development" but in actual reality mostly are about performance. In a way, this is a border line case, as it neatly illustrates Jackall's (1988) idea of “dexterity with symbols” by which he typically means the dexterous use of euphemisms. Having said that, it is hard to go through an 
appraisal process without thinking that the development aspect of the enterprise has the distinct look and feel of bullshit.

It is difficult to overstate how attractive the proposition of bullshitting around the conflicting demands of being egalitarian in a hierarchical set-up may be for any prospective manager. Think about it. As a manager, some part of the buck stops at you. Yet, you often have little leeway in dealing with this explicitly: while being completely egalitarian may be seen as abdicating your role as a manager, being authoritarian in modern organizations likely leads straight to HR training programs in conflict management, a collapse in authority among subordinates, being demoted or all above. In the face of egalitarian authoritarianism, there is small wonder why modern managers squirrel for anything that gives them a sense of agency, be it inscrutable, working in mysterious ways and ultimately corrosive. When the setting of direction extends beyond the immediate moment, the need for bullshit becomes even more pronounced.

Strategizing as bullshit. Managerial talk is generally expected to be truthful. At the same time, however, it often involves describing futures for which existing words are inadequate (Thayer, 1988; Weick, 1987). Strategizing, understood as attempts to define and achieve such futures (Gulbrandsen \& Just, 2016), is therefore likely to depict reality in a language that differs from - perhaps even defies - the immediate experiences of employees and other audiences. As Shotter (1993, p. 153) explains: "...much of what [leaders] talk about has a contested nature; that is, [the] talk is not about something which already actually exists, but is about what might be, what could be the case, or what something should be like". Management communication, thus, is structurally conditioned towards the practice of bullshitting, often with the help of professionals in public relations and marketing (e.g., Jackall, 1988; Fincham, 1999). 
As Frankfurt (2005) and Kelly (2014) point out, communicators are inclined to produce bullshit especially when they talk about issues that exceed their knowledge, but fail to confess the limits of their understanding. This condition is practically endemic in strategizing processes where managers frequently need to articulate interesting and inspiring strategic goals for their organizations without fully understanding what is going on. Carlsberg, for instance, recently launched a new CSR strategy called Together Towards Zero. One of its main aims is to reduce irresponsible drinking to zero. Although a manager's immediate credibility might be enhanced, if (s)he simply admits that goals were formulated without a full insight into the matter, such approach runs the risk of demotivating members and other stakeholders. These audiences may want to know - because they have their jobs, political positions and/or money invested - that the organization is likely to become better, for example more sustainable and profitable.

Even if uncertainty is high, the success of visionary strategies hinges on the ability of managers to instil confidence (Weick, 1987). Strategizing therefore often describes future realities in an assertive and bombastic language as if these realities were almost already achieved. Christensen, Morsing and Thyssen (2013) refer to such language as "aspirational talk", defined as self-descriptive claims to which current organizational practices cannot yet live up. While such descriptions, according to Christensen et al., have self-transformative potential because they articulate a horizon of excellence to which employees, NGOs and other stakeholders can hold the organization accountable (see also Lunheim, 2005), someone's aspiration is often another one's bullshit and may therefore not be taken seriously. 


\section{LETTING THE SHIT PASS}

Bullshit is occasionally called by employees or other stakeholders (e.g., Llewelyn \& Harrison, 2006). But often it is allowed to pass. There may be multiple reasons why this is the case, including fear, naïveté, politeness, indifference or cynicism. Either way, organizational members - or bullshitees - play a significant role in co-producing situations where bullshit can exist and prosper. Hereby, we do not imply that bullshitees are complicit in bullshitting, as some scholars suggest (Pennycook et al., 2015; see also Lear, 2005), rather that bullshit emerges in situations where a certain receptivity to that particular type of talk is present. The fact that much bullshit is left uncalled indicates some mutual understanding, if not consent, of the role bullshit plays in organizations.

Accordingly, we focus below on the role of bullshitees in situations where bullshit is expected, albeit not necessarily accepted. Such situations, we believe, are legion in complex organizations where managers need to straddle multiple interests and concerns (e.g., Brunsson, 2003; Eisenberg, 2007). As we have seen, Pennycook et al. (2015) suggest that certain audiences are more uncritically receptive to bullshit than others. That may well be the case - some recipients seem to consume bullshit at face value - although the prevalence of bullshit in academe challenges simple distinctions between bullshit receptivity and bullshit sensitivity. Instead, we argue that the roles of bullshitees are more fluid positions that receivers might, unwittingly or not, step in and out of, depending on the specific context.

Some types of managerial talk, for example, concern issues of little interest or importance to the average employee. Relevance, thus, is likely to influence the bullshitee position. Even if relevance is high, vacuous talk, identified as bullshit, may be allowed to pass if it emanates from managers employees respect or sympathize 
with. The chosen bullshitee role, in other words, depends on the perception of the communicator. Bullshit, however, may also be allowed to pass when respect for the communicator is low, for example when it is acknowledged that the speech situation calls for a certain type of vague talk. The setting, thus, is likely to shape bullshit receptivity. In addition, organizational members may well perceive the bullshit, but refrain from calling it because they are uncertain about how their colleagues and other participants experience the situation. In this case, the social interaction may explain why the shit is not called. Bullshitees may also hold back in calling the bullshit because the ability to see through the shit creates a sense of superiority that the call could potentially undermine. In this case, the maintenance of a particular self-identity may explain the behavior. Finally, bullshit which is not called in the very moment it is experienced may be called later as the message is digested and perhaps discussed with others. Here, it is temporality that shapes how and if bullshit is called. The combined effects of the relevance of the topic, the communicator, the setting, the social interaction, the self-identity and temporality influence the dynamics between bullshit, bullshitters and bullshitees and may explain why bullshit that is identified in the situation is only "called" silently or indirectly.

Exactly how bullshit is consumed is, of course, an empirical question that needs to be studied more closely in order to fully understand how this particular type of communication might be shaping organizations. One step in that direction is to study specific bullshitee positions - e.g., naïve, indifferent, skeptic, or cynic - at play in concrete commanding or strategizing processes. While the naïve bullshitee position, for example, might help rendering the bullshitter an honest well-meaning person, the skeptic is likely to inject struggle and disbelief into the process and a (vain) search for an underlying message. The cynical bullshitee might wink back to the bullshitter with 
a bluff and a fake, like two poker players in a low stakes hand. (S)he might be convinced that the message is bullshit, but find it worthwhile to play on regardless. One reason might be that calling the shit publicly is likely to have costs and repercussions, including taking responsibility to engage honestly and sincerely about the matter at hand.

Consider a slogan that was prominently displayed at Copenhagen Business School (CBS) until recently: "CBS - where University means Business". Since university in no way and in no language means business, we can rest assured that the statement operates outside normal truth claims. Is it bullshit? It certainly qualifies as a statement, while being suggestive and clever, that is difficult - impossible - to clarify (Cohen, 2006). It is a juxtaposition of very different things, suggesting that they are the same or closely related. A bullshittee in the indifferent mode might take a glance at the message, shake it off, and move on. When in a naïve mode, there might be an inclination to assume that the sender of this message attempts to communicate something important and profound. Maybe business is an important part of a university? Maybe university is important for business?

A bullshittee in the skeptical mode, on the other hand, may be inclined to distrust organizational messages, but give them an initial benefit of the doubt. The skeptical bullshitee, in other words, is uncertain whether there is a sincere attempt to communicate authentically, but takes this as an open question worthy to explore. We can expect an impulse to make sense of the statement in good faith but also, perhaps, that the skeptical bullshitee will call bullshit eventually. This is not to claim that the skeptical bullshitee necessarily will make the judgment that the sender of the message is willfully bullshitting him or her. Maybe there is something sincere at heart that just 
was expressed in a bullshit way. Perhaps the (formal) sender was bamboozled by too clever creatives from expensive advertising agencies.

A bullshitee in the cynical mode, finally, will call the shit immediately, but silently, and usually only for him/herself. (S)he is at once convinced that the message is bullshit but finds it worthwhile to play on regardless. One reason may be the sense of satisfaction that comes from unmasking what is going on, the feeling of superiority that emerges when you call a bluff or anticipate a feint. Another reason may be that calling the bullshit publicly is, as pointed out above, hard work. There are many situations where this is, at least from the perspective of the cynical bullshitee, uneconomical or beside the point. Most faculties we talked to at CBS seemed to consider the slogan from a cynical bullshittee point of view. While prominently displayed at buildings and in promotion materials, it was rarely, if ever, used by faculty members to characterize their workplace, neither in educational settings, nor in research arenas. When brought up in conversation, the typical reaction was a knowing smile and a change of subject.

Indifferent, naïve, skeptical and cynical are just a few of the many positions available to bullshitees in organizations. To complicate matters, these positions are often fluid. What looks like an indifferent (or naïve) attitude toward bullshit in the specific situation - because it is not immediately confronted or "called" by the audience - may cover a more subtle type of cynicism or resistance that can surface later or in other contexts (Mumby et al., 2017; Ybema \& Hovers, 2017). Letting the bullshitter "get away" with the bullshit, in other words, is not necessarily a tolerance for such talk in organizational practice. Bullshit piles up and may over time undermine trust and authority. 


\section{LOOKING AHEAD}

This essay addresses the organizational significance of bullshit as a social and communicative phenomenon. As our discussion has illustrated, the meaning and impact of bullshit in organizations is diverse and contextual. While bullshit is expected and perhaps even encouraged in some situations, it may be castigated and denounced in others. Tolerance toward bullshit - or lack thereof - is likely to vary, depending on the expectations for the situation and the relationship between the communicator and its audience.

Our focus on organizational bullshit does not suggest that organizations are the only or primary repositories of bullshit in society, that managerial talk per se is bullshit, or that managers are necessarily bullshitters. But we do suggest that bullshit attains a specific significance in contemporary organizations where increased complexity, multiple interests, and conflicting agendas tend to promote particular communicative practices that in some situations may suitably be labeled "bullshit." As an analytical lens, bullshit allows us to study unclear, vague, misleading or nonsensical dimensions of corporate and managerial talk and their different social and managerial functions. While the notion of bullshit has a critical edge that directs attention to deceptive and manipulative practices, recognition of how and what it performs provides an insight into the tensions and dilemmas that shape much communication in the organizational context.

Future research in organization studies needs to further specify how bullshit is used in organizations, how we encounter it, how it encroaches upon other organizational practices and what its ramifications are for managers and other organizational members. Specifically, such research needs to consider situational factors such as the setting in which bullshit occurs (e.g., formal or informal), its 
reception among participants (in the moment the bullshit is conveyed as well as over time), the positions and power of its producers, its directionality (e.g., one-way or dialogical), the level of improvisation (e.g., spontaneous versus crafted), and the scope of its consequences (including the consequences of dismissing bullshit altogether). Research in this direction would not only further contextualize the role of bullshit in organizations, but provide significant insight into the many different dimensions of organizational communication.

Some reflexivity is in order. We should take a look in the mirror and reflect on how academic research may feed the demand for bullshit in organizational contexts. The literature on management consultancy, for example, frequently observes that (hairsplitting) academic concepts are co-opted by the consultancy industry to exploit the anxieties of chronically out of depth managers. The cycles of management fashions are well documented (Kieser, 1997). While such cycles may have rational foundations, they are invariably fed by bullshit representations of (bad) metaphors and (poorly coined) concepts, and the fashions themselves are invariably sold as panaceas to all organizational ills. Having said that, while we as scholars should not assume to have a privileged view on bullshit, we often can expose the blind spots that organizations are subject to. Empirical research can act as a process of second-order observation - that is, scholars' observations observing previous observations by organizational members (e.g., in those situations where organizations cannot uncover their own bullshit). Although such observations do not bring the researcher closer to the object of observation, it can unveil how cognitive organizational reality came into being (Luhmann, 1993).

Finally, future research needs to take a close look at the interaction effects between the bullshit, the bullshitter, and the bullshitee. In particular, the role of the 
bullshitee deserves more scrutiny, as we hardly have any systematic insights into what drives receptivity to (or tolerance for) bullshit. As many organizations seem to be quite tolerant vis-à-vis the bullshit that is produced in and around them, such scholarly work could allow us to better understand a number of organizational phenomena, for example structural and cultural inertia. Research in this direction can be coupled to contemporary discussions in a number of fields relevant to organization studies, including, but not limited to: management fashions and ideas, corporate social responsibility, reputation management, and hypocrisy. 


\section{TABLES}

Table 1: Different understandings of bullshit

\begin{tabular}{|c|c|c|c|}
\hline Bullshit As... & $\begin{array}{l}\text { Key Reference / } \\
\text { Author }\end{array}$ & $\begin{array}{l}\text { Underlying } \\
\text { Understanding of } \\
\text { Bullshit }\end{array}$ & Main Focus \\
\hline & Frankfurt (2005) & $\begin{array}{l}\text { "[...] lack of connection } \\
\text { to a concern with truth } \\
{[\ldots] "(\text { p. } 33)}\end{array}$ & $\begin{array}{l}\text { the } \\
\text { bullshitter }\end{array}$ \\
\hline $\begin{array}{c}\text { Willful } \\
\text { Misrepresentation }\end{array}$ & Kelly (2014) & $\begin{array}{l}\text { "[...] phoniness in the } \\
\text { communication from an } \\
\text { agent who knows what } \\
\text { his audience is willing } \\
\text { to let him get away with } \\
{[\ldots] " \text { (p. 166) }}\end{array}$ & $\begin{array}{l}\text { the } \\
\text { bullshitter }\end{array}$ \\
\hline \multirow[b]{2}{*}{$\begin{array}{l}\text { Unclarifiable } \\
\text { Unclarity }\end{array}$} & Cohen (2006) & $\begin{array}{l}\text { "unclarifiable unclarity" } \\
\text { (p. 135) - discourses } \\
\text { that cannot be rendered } \\
\text { clear or unobscure }\end{array}$ & the bullshit \\
\hline & $\begin{array}{l}\text { Pennycook et al. } \\
\text { (2015) }\end{array}$ & $\begin{array}{l}\text { "pseudo-profound } \\
\text { bullshit" (p. 549) } \\
\text { deliberately designed to } \\
\text { simulate sophistication } \\
\text { by obscuring or evading } \\
\text { clarity }\end{array}$ & $\begin{array}{l}\text { the } \\
\text { bullshitee }\end{array}$ \\
\hline
\end{tabular}




\section{REFERENCES}

Allen, D.E., Allen, R.S., McGoun, E.G. (2012). Bull markets and bull sessions. Culture and Organization, 18(1), 15-31.

Argyris, C. (1990). Overcoming organizational defenses. Boston, MA: Allyn and Bacon.

Barnes, J.A. (1994). A pack of lies: Towards a sociology of lying. New York, NY: Cambridge University Press.

Berenson, T. (2015). Donald Trump calls for deporting undocumented immigrants, letting some back in. Available at: http://time.com/3977763/donald-trumpimmigration-policy/

Brunsson, N. (2003). The organization of hypocrisy. Talk, decisions and actions in organizations, 2nd ed. Oslo: Liber.

Christensen, L. T., Morsing, M., \& Thyssen, O. (2013). CSR as aspirational talk. Organization, 20(3), 372-393.

Cohen, G.A. (2006). Deeper into bullshit. In G.L. Hardcastle \& G.A. Reisch. (Eds.) Bullshit and philosophy (pp. 117-135). Chicago/La Salle, IL: Open Court.

Deetz, S. (1992). Democracy in an age of corporate colonization: Developments in communication and the politics of everyday life. Albany, NY: State University of New York Press.

Eisenberg, E.M. (1984). Ambiguity as strategy in organizational communication. Communication Monographs, 51, 227-242.

Eisenberg, E.M. (2007). Strategic ambiguities. Essays on communication, organization and identity. Thousand Oaks: Sage.

Fincham, R. (1999). The consultant-client relationship: Critical perspectives on the management of organizational change. Journal of Management Studies, 36(3), 335-351.

Fleming, P., \& Spicer, A. (2014). Power in management and organization science. Academy of Management Annals, 8(1), 237-298.

Frankfurt, H. (2016). Donald Trump is BS, Says Expert in BS. Available at: http://time.com/4321036/donald-trump-bs/

Frankfurt, H. (2005). On Bullshit. Princeton and Oxford: Princeton University Press.

Graeber, D. (2018). Bullshit jobs: A theory. New York: Simon \& Schuster.

Gulbrandsen, I.T., \& Just, S.N. (2016). Strategizing communication. Theory and practice. København: Samfundslitteratur.

Hardcastle, G.L., \& Reisch, G.A. (Eds.) (2006). Bullshit and philosophy. Guaranteed to get perfect results every time. Chicago/La Salle, Ill: Open Court.

Heer, J. (2018). Worse Than a Liar. The New Republic, March 15, 2018. https://newrepublic.com/article/147504/worse-liar-trump-lies-trudeau

Jackall, R. (1988). Moral mazes. The world of corporate managers. New York: Oxford University Press. 
Kelly, M.R. (2014). Bullshit as the absence of truthfulness. International Studies in Phenomenology and Philosophy 2(2), 165-88.

Kessler, G. Rizzo, S., \& Kelly, M. (2018). President Trump has made 6,420 false or misleading claims over 649 days. Available at: https://www.washingtonpost.com/politics/2018/11/02/president-trump-hasmade-false-or-misleading-claims-over-days/?utm term $=.07 \mathrm{aa} 034 \mathrm{e} 6534$

Keyes, R. (2004). The post-truth era: Dishonesty and deception in contemporary life. New York: St. Martin's.

Kieser, A. (1997). Rhetoric and myth in management fashion. Organization, 4(1), 49 74.

Kimbrough, S. (2006). On letting it slide.” In G.L. Hardcastle \& G.A. Reisch. (Eds.) Bullshit and philosophy (pp. 3-18). Chicago/La Salle: Open Court.

Lear, J. (2005). Whatever. New Republic 232(10), 23-25.

Llewellyn, N. \& Harrison, A. (2006). Resisting corporate communications: Insights into folk linguistics. Human Relations, 59(4): 567-596.

Luhmann, N. (1993). Deconstruction as second-order observing. New Literary History, 24(4), 763-782.

Lunheim, R. (2005). Confessions of a corporate window-dresser. Leading Perspectives, Summer: 6-7.

Maes, H., \& Schaubroeck, K. (2006). Different kinds and aspects of bullshit. In G.L. Hardcastle \& G.A. Reisch. (Eds.) Bullshit and philosophy (pp. 171-182). Chicago/La Salle: Open Court.

Manjoo, F. (2008). True enough: Learning to live in a post-fact society. Hoboken, NJ: John Wiley \& Sons.

Mears, D.P. (2002). The ubiguity, functions, and contexts of bullshit. Journal of Mundane Behavivior, 3(2), 233-256.

Mumby, D.K., Thomas, R., Martí, I, \& Seidl, D. (2017). Resistance redux. Organization Studies, 38(9), 1157-1183.

Myers, G., \& Myers, M. (1991). The dynamics of human communication: A laboratory approach. 6th Ed. McGraw-Hill.

Pennycook, G., Cheyne, J. A., Barr, N., Koehler, D. J., \& Fugelsang, J. A. (2015). On the reception and detection of pseudo-profound bullshit. Judgment and Decision Making, 10(6), 549-563.

Porter, M. E., \& Kramer, M. R. (2002). The competitive advantage of corporate philanthropy. Harvard Business Review, 80(12), 56-69.

Porter, M. E., \& Kramer, M. R. (2011). Creating shared value. Harvard Business Review, 89(1/2), 62-77.

Reisch, G.A. (2006). The pracmatics of bullshit, intelligently designed. In G.L. Hardcastle \& G.A. Reisch. (Eds.) Bullshit and philosophy (pp. 33-47). Chicago/La Salle, IL: Open Court.

Senge, P. M. (1990). The fifth discipline: The art and practice of learning. New York: Doubleday. 
Shotter, J. (1993). Conversational realities. Constructing life through language. London: Sage.

Spicer, A. (2013). Shooting the shit: the role of bullshit in organisations. M@n@gement,16(5),653-666.

Spicer, A. (2017). Business bullshit. London et al.: Routledge.

Teitge, D.J. (2006). Rhetoric is not bullshit. In G.L. Hardcastle \& G.A. Reisch. (Eds.) Bullshit and philosophy (pp. 229-240). Chicago/La Salle, IL: Open Court.

Thayer, L. (1988). Leadership/communication: A critical review and a modest proposal. In G.M. Goldhaber \& G.A. Barnett (Eds.), Handbook of organizational communication (pp. 231-263). Norwood, NJ: Ablex.

Vaughan, D. (1996). The Challenger launch decision: Risky technology, culture, and deviance at NASA. Chicago: University of Chicago Press.

Weick, K.E. (1987), Substitutes for strategy. In D.J.Teece (Ed.) The competitive challenge. Strategies for industrial innovation and renewal. (pp. 221-233). Cambridge, MA: Ballinger.

Weick, K.E. \& Sutcliffe, K.M. (2015). Managing the unexpected: Sustained performance in a complex world. Hoboken: Wiley.

Ybema, S., \& Horvers, M. (2017). Resistance through compliance: The strategic and subversive potential of frontstage and backstage resistance. Organization Studies, 38(9), 1233-1251. 